\title{
MODEL PERSEDIAAN ECONOMIC PRODUCTION QUANTITY (EPQ) DENGAN MEMPERTIMBANGKAN DETERIORASI
}

\author{
IRA SORAYA \\ Program Studi Matematika, \\ Fakultas Matematika dan Ilmu Pengetahuan Alam, Universitas Andalas, \\ Kampus UNAND Limau Manis Padang, Indonesia, \\ irasoraya.hasanah@gmail.com
}

\begin{abstract}
Abstrak. Persediaan dapat mengalami kerusakan atau deteriorasi sehingga persediaan tidak dapat disimpan dalam jangka waktu tak terhingga untuk memenuhi permintaan yang akan datang. Model persediaan Economic Production Quantity (EPQ) adalah salah satu model persediaan yang dapat digunakan untuk menyelesaikan masalah pengendalian persediaan. Dalam tulisan ini dikembangkan model persediaan EPQ tanpa deteriorasi dan dengan mempertimbangkan deteriorasi. Tujuannya adalah menentukan banyaknya produksi yang meminimumkan total biaya persediaan. Model diilustrasikan dengan contoh yang diselesaikan secara numerik dengan menggunakan software LINGO. Kemudian dilakukan analisis sensitivitas terhadap kedua model. Model persediaan tanpa deteriorasi memiliki solusi optimum sedikit lebih kecil jika dibandingkan dengan model persediaan dengan deteriorasi.
\end{abstract}

Kata Kunci: Deteriorasi, persediaan EPQ, solusi optimum, analisis sensitivitas

\section{Pendahuluan}

Persediaan dapat mengalami kerusakan atau penurunan kualitas dari waktu ke waktu sehingga persediaan tidak selalu dapat disimpan atau ditimbun dalam jangka waktu yang tak terhingga untuk memenuhi permintaan yang akan datang. Barangbarang yang biasa digunakan seperti buah-buahan, bahan makanan, sayuran, produk farmasi dan komponen-komponen elektronik dapat terdeteriorasi (rusak) diakibatkan penyimpanan yang terlalu lama dibanding periode normal penyimpanannya sehingga tidak dalam kondisi sempurna untuk memenuhi permintaan yang akan datang. Persediaan yang terdeteriorasi adalah persediaan yang rusak, busuk, kering dan menguap sehingga hilangnya manfaat atau nilai marginal suatu barang atau menurunnya fungsi suatu barang dari kondisi aslinya.

Efek kerusakan pada persediaan pertama kali dikembangkan oleh Ghare dan Schrader [4]. Mereka mengamati bahwa seiring dengan waktu barang tertentu dapat menyusut dengan proporsi yang didekati oleh fungsi eksponensial negatif. Pengamatan ini menghasilkan model persediaan barang dengan proses kerusakannya dinyatakan oleh persamaan diferensial

$$
\frac{d I(t)}{d t}+\theta I(t)=-f(t)
$$


dimana $\theta$ adalah tingkat deteriorasi yang konstan, $I(t)$ adalah level persediaan pada waktu $t$ dan $f(t)$ adalah tingkat permintaan pada waktu $t$.

Dalam proses produksi sering kali perusahaan mengalami masalah untuk memperoleh rencana produksi yang paling optimal yang dapat memenuhi permintaan. Model Economic Production Quantity (EPQ) adalah salah satu model pengendalian persediaan. Dalam artikel ini, kita mengembangkan model EPQ tanpa adanya deteriorasi dan dengan mempertimbangkan deteriorasi. Kuantitas kehilangan produksi karena mesin rusak/usang, kerusakan produksi dan lain sebagainya juga dipertimbangkan. Solusi dari biaya total persediaan diilustrasikan dengan contoh yang diselesaikan secara numerik dengan menggunakan software LINGO. Selanjutnya dilakukan dianalisis sensitivitas terhadap kedua model.

\section{Model Persediaan EPQ}

Metode EPQ merupakan model persediaan dimana pengadaan bahan baku berupa komponen tertentu diproduksi secara massal dan dipakai sendiri sebagai sub komponen suatu produk jadi oleh perusahaan. Deskripsi model persediaan EPQ dapat dilihat melalui Gambar 1.

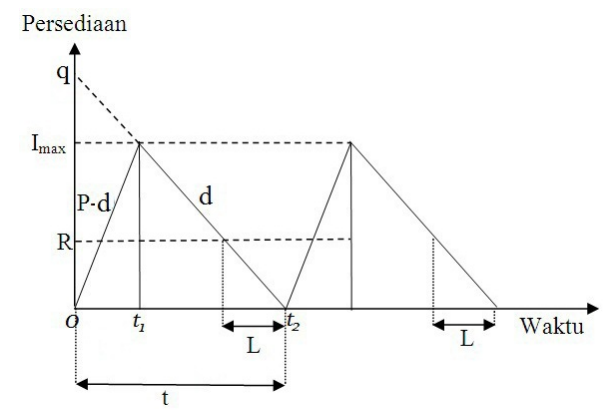

Gambar 1. Grafik Persediaan EPQ

Jumlah produksi selama waktu $t$ harus memenuhi jumlah permintaan $(d)$ selama waktu $t$ tersebut, dinotasikan sebagai: $q=d t$. Produksi dilakukan pada masa $\left[0, t_{1}\right]$ dengan tingkat produksi sebesar $P$, seiring dengan pemenuhan permintaan. Karena jumlah produksi adalah $q=t_{1} . P$, maka $t_{1}=\frac{q}{P}$. Pada masa ini, persediaan mencapai maksimum, yaitu sebesar $I_{\max }=t_{1}(P-d)$, sedangkan rata-rata persediaan adalah $\bar{I}=t_{1}\left(\frac{P-d}{2}\right)$. Pada masa $\left[t_{1}, t_{2}\right]$ proses produksi berhenti, sedangkan permintaan tetap dipenuhi, sehingga terjadinya penurunan persediaan sebesar $d$. Jika persediaan telah mencapai tingkat $R$, maka harus dilakukan pengadaan bahan baku untuk proses produksi selanjutnya selama masa $L[5]$. Dengan mensubtitusikan $t_{1}$, maka rata-rata persediaan menjadi

$$
\frac{q}{P}\left(\frac{P-d}{2}\right)=\frac{q(P-d)}{2 P}=\frac{q}{2}-\frac{q d}{2 P}=\left(1-\frac{d}{P}\right) \frac{q}{2},
$$

dimana $C_{1}$ adalah biaya simpan tiap satuan waktu. Karena jumlah putaran pro- 
duksi adalah $\frac{d}{q}$, maka biaya rata-rata pengadaan adalah sebesar $\frac{d}{q} C_{2}$, dimana $C_{2}$ adalah biaya pengadaan bahan baku tiap putaran produksi. Jadi total biaya persediaan adalah

$$
\begin{aligned}
Z & =\text { biaya simpan }+ \text { biaya pengadaan } \\
& =\frac{d}{q} C_{2}+\left(1-\frac{d}{P}\right) \frac{q}{2} C_{2} ; \quad q>d .
\end{aligned}
$$

Dari turunan pertama $Z$ terhadap $q$ yang disamakan dengan nol diperoleh jumlah produksi optimal $\left(q^{*}\right)$ dalam satu putaran produksi yaitu

$$
q^{*}=\sqrt{\frac{2 d C_{2}}{\left(1-\frac{d}{P}\right) C_{1}}} .
$$

Sehingga diperoleh total biaya persediaan

$$
Z^{*}=\frac{d}{q^{*}} C_{2}+\left(1-\frac{d}{P}\right) \frac{q^{*}}{2} C_{1}
$$

\section{Asumsi dan Notasi}

Asumsi yang digunakan dalam mengembangkan model adalah:

(1) Model dikembangkan untuk persediaan produk tunggal.

(2) Model dikembangkan untuk persediaan barang setengah jadi (work in process) dan barang jadi.

(3) Tingkat produksi dan permintaan konstan.

(4) Tidak terjadinya kekurangan persediaan (shortages).

(5) Tidak ada penggantian dan perbaikan kerusakan alat selama periode $T$.

(6) Bahan baku tersedia sewaktu diperlukan untuk proses produksi (lead time/waktu tunggu nol).

Selanjutnya notasi yang digunakan dalam mengembangkan model adalah:

$k$ : jumlah produksi per satuan waktu,

$d:$ jumlah permintaan per satuan waktu,

$\phi:$ persentase kerusakan selama produksi per satuan waktu,

$k(1-\phi)$ : produksi aktual per satuan waktu,

$C_{1}$ : konstanta biaya simpan per satuan item,

$r$ : konstanta ongkos pembelian bahan baku per satuan item,

$b$ : konstanta biaya persiapan produksi per pesanan,

$p$ : konstanta harga penjualan produksi per satuan item,

$\theta$ : tingkat deteriorasi (konstan) dalam persediaan per satuan wantu,

$t_{1}$ : waktu produksi per siklus,

$q$ : jumlah produksi aktual yang diterima per siklus $=k(1-\phi) t_{1}$,

$t_{2}$ : panjang dari masing-masing siklus,

$T$ : periode keseluruhan,

$q_{1}$ : tingkat persediaan selama periode produksi $\left(0 \leq t \leq t_{1}\right)$,

$q_{2}$ : tingkat persediaan selama periode produksi dihentikan $t_{1} \leq t \leq t_{2}$. 


\section{Model Persediaan EPQ Tanpa Deteriorasi}

Deskripsi model persediaan EPQ tanpa terdeteriorasi dapat dilihat pada Gambar 2 .

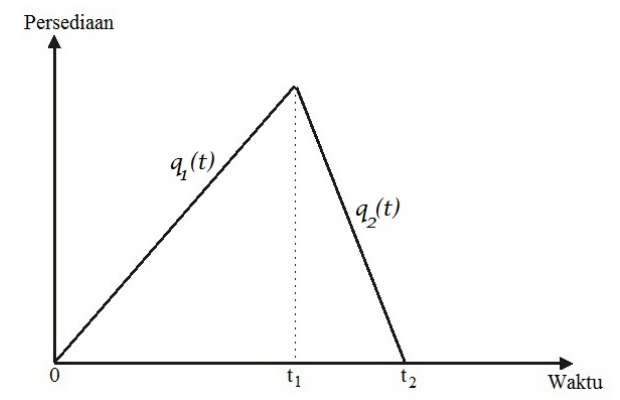

Gambar 2. Grafik Persediaan EPQ tanpa deteriorasi

Pada saat $t=0$ tingkat persediaan adalah nol. Pada periode produksi $\left[0, t_{1}\right]$ tingkat persediaan dipengaruhi oleh banyaknya produksi aktual dan tingkat permintaan. Pada periode $\left[t_{1}, t_{2}\right]$ dimana produksi dihentikan, tingkat persediaan hanya dipengaruhi oleh tingkat permintaan. Karena adanya tingkat permintaan yang terus dipenuhi, hal ini mengakibatkan tingkat persediaan mengalami penurunan dan mencapai nol pada saat $t=t_{2}$. Siklus kemudian berulang untuk seluruh periode $T$. Tingkat persediaan pada periode $\left[0, t_{2}\right]$ dapat dinyatakan oleh persamaan diferensial berikut.

dimana

$$
\begin{aligned}
\frac{d q_{1}}{d t}=k(1-\phi)-d ; & 0 \leq t \leq t_{1}, \\
\frac{d q_{2}}{d t}=-d ; & t_{1} \leq t \leq t_{2}
\end{aligned}
$$

$$
q_{1}(0)=0 ; \quad q_{1}\left(t_{1}\right)=q_{2}\left(t_{1}\right) \quad \text { dan } \quad q_{2}\left(t_{2}\right)=0 .
$$

Solusi dari persamaan (4.1) adalah sebagai berikut

$$
\begin{aligned}
& q_{1}=[k(1-\phi)-d] t \quad \text { untuk } \quad 0 \leq t \leq t_{1}, \\
& q_{2}=d\left(t_{2}-t\right) \quad \text { untuk } \quad t_{1} \leq t \leq t_{2} .
\end{aligned}
$$

Dengan menggunakan kondisi $q_{1}\left(t_{1}\right)=q_{2}\left(t_{1}\right)$ diperoleh

$$
t_{2}=\frac{q}{d}
$$

Biaya-biaya yang diakibatkan karena adanya persediaan adalah:

(1) Biaya simpan (holding cost/HC) dapat dirumuskan sebagai berikut :

$$
\begin{aligned}
H C & =C_{1}\left\{\int_{0}^{t_{1}} q_{1}(t) d t+\int_{t_{1}}^{t_{2}} q_{2}(t) d t\right\} \\
& =C_{1}\left\{(k(1-\phi)-d) \frac{t_{1}^{2}}{2}+\frac{d}{2}\left(t_{2}-t_{1}\right)^{2}\right\} .
\end{aligned}
$$


54 Ira Soraya

(2) Biaya kehilangan produksi karena mesin rusak $(L P)$ dapat dirumuskan sebagai berikut :

$$
L P=r k \phi t_{1} .
$$

(3) Biaya persiapan produksi atau set-up cost dinotasikan dengan $b$.

Jadi biaya total persediaan untuk seluruh perencanaan selama periode $T$ adalah

$$
\begin{aligned}
Z(q, d) & =(H C+L P+b) \frac{T}{t_{2}}, \\
& =\left\{C_{1}\left\{(k(1-\phi)-d) \frac{t_{1}^{2}}{2}+\frac{d}{2}\left(t_{2}-t_{1}\right)^{2}\right\}+r k \phi t_{1}+b\right\} \frac{T}{t_{2}}, \\
& =d A+B,
\end{aligned}
$$

dimana,

$$
\begin{aligned}
A & =\frac{r \phi T}{1-\phi}-\frac{C_{1} q T}{2 k(1-\phi)}+\frac{b T}{q}, \\
B & =\frac{C_{1} q T}{2} .
\end{aligned}
$$

\section{Model Persediaan EPQ dengan Mempertimbangkan Deteriorasi}

Deskripsi model persediaan EPQ dengan mempertimbangkan deteriorasi dapat dilihat pada Gambar 3.

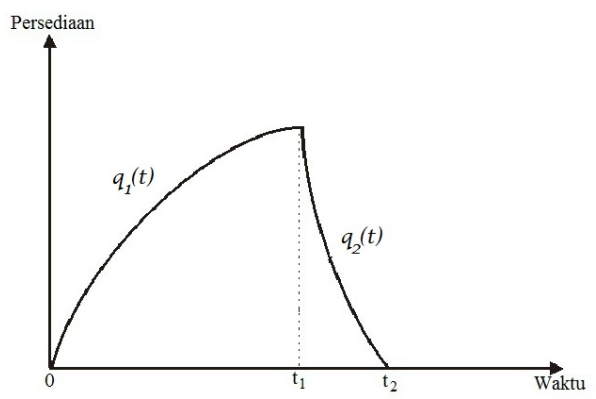

Gambar 3. Grafik Persediaan EPQ dengan deteriorasi

Dari Gambar 3 dapat dilihat bahwa tingkat persediaan adalah nol pada saat $t=0$. Proses produksi dimulai pada saat $t=0$ dan berlanjut hingga $t=t_{1}$, pada periode ini persediaan berkurang karena adanya deteriorasi dan permintaan. Persediaaan mencapai tingkat maksimum pada saat $t=t_{1}$. Tingkat produksi yang diamati menjadi lebih kecil dibanding tingkat produksi yang diinginkan ketika terjadinya kerusakan mesin. Proses produksi dihentikan pada periode $\left[t_{1}, t_{2}\right]$, sedangkan permintaan tetap dipenuhi dan deteriorasi tetap terjadi. Akibatnya persediaan semakin lama semakin berkurang dan habis pada saat $t=t_{2}$. Tingkat persediaan 
pada periode $\left[0, t_{2}\right]$ dapat dinyatakan dalam persamaan diferensial berikut:

$$
\begin{aligned}
& \frac{d q_{1}}{d t}+\theta q_{1}=k(1-\phi)-d ; \quad 0 \leq t \leq t_{1} \\
& \frac{d q_{2}}{d t}+\theta q_{2}=-d ; \quad t_{1} \leq t \leq t_{2}
\end{aligned}
$$

dimana,

$$
q_{1}(0)=0 ; \quad q_{1}\left(t_{1}\right)=q_{2}\left(t_{1}\right) \quad \text { dan } \quad q_{2}\left(t_{2}\right)=0 .
$$

Solusi persamaan di atas adalah

$$
\begin{aligned}
& q_{1}=\frac{k(1-\phi)-d}{\theta}\left(1-e^{-\theta t}\right) \quad \text { untuk } \quad 0 \leq t \leq t_{1}, \\
& q_{2}=\frac{d}{\theta}\left(e^{\theta\left(t_{2}-t\right)}-1\right) \quad \text { untuk } \quad t_{1} \leq t \leq t_{2} .
\end{aligned}
$$

Dengan menggunakan kondisi $q_{1}\left(t_{1}\right)=q_{2}\left(t_{1}\right)$ diperoleh

$$
t_{2}=\frac{q}{d}\left(1+\frac{\theta t_{1}}{2}\right)-\frac{\theta q^{2}}{2 d^{2}}
$$

Biaya-biaya yang diakibatkan karena adanya persediaan adalah:

(1) Biaya simpan (holding cost/HC) adalah

$$
\begin{aligned}
H C & =C_{1}\left\{\int_{0}^{t_{1}} q_{1}(t) d t+\int_{t_{1}}^{t_{2}} q_{2}(t) d t\right\} . \\
& \approx C_{1}\left[(k(1-\phi)-d)\left(\frac{t_{1}^{2}}{2}-\frac{\theta t_{1}^{3}}{6}\right)+d\left\{\frac{\left(t_{2}-t_{1}\right)^{2}}{2}+\frac{\theta\left(t_{2}-t_{1}\right)^{3}}{6}\right\}\right] .
\end{aligned}
$$

(2) Biaya kehilangan produksi karena mesin rusak yang dinotasikan dengan $L P$ adalah

$$
L P=r k \phi t_{1} .
$$

(3) Biaya kehilangan persediaan karena terjadinya deteriorasi yang dinotasikan $L S$ adalah

$$
\begin{aligned}
L S & =p \theta\left\{\int_{0}^{t_{1}} q_{1}(t) d t+\int_{t_{1}}^{t_{2}} q_{2}(t) d t\right\} \\
& =p\left[k(1-\phi) t_{1}-d t_{2}\right] .
\end{aligned}
$$

(4) Biaya persiapan produksi atau set-up cost yang dinotasikan dengan $b$.

Jadi, biaya total persediaan untuk seluruh perencanaan selama periode $T$ adalah

$$
\begin{aligned}
Z(q, d, \theta)= & (H C+L S+L P+b) \frac{T}{t_{2}}, \\
= & {\left[( C _ { 1 } + p \theta ) \left\{(k-k \phi-d)\left(\frac{t_{1}^{2}}{2}-\frac{\theta t_{1}^{3}}{6}\right)+\frac{d\left(t_{2}-t_{1}\right)^{2}}{2}\right.\right.} \\
& \left.\left.+\frac{d \theta\left(t_{2}-t_{1}\right)^{3}}{6}\right\}+r k \phi t_{1}+b\right] \frac{T}{t_{2}}, \\
= & A_{1}+\theta A_{2}+d A_{3}-d \theta A_{4}-\frac{\theta}{d} A_{5},
\end{aligned}
$$


$56 \quad$ Ira Soraya

dimana

$$
\begin{aligned}
& A_{1}=\frac{C_{1} q T}{2}, \\
& A_{2}=\left(p q+\frac{r q \phi}{1-\phi}+b\right) \frac{T}{2}, \\
& A_{3}=\left\{\frac{b}{q}+\frac{r \phi}{1-\phi}-\frac{C_{1} q}{2 k(1-\phi)}\right\} \frac{T}{2}, \\
& A_{4}=\left\{\frac{r q \phi+(b+p q)(1-\phi)}{k(1-\phi)^{2}}-\frac{C_{1} q^{2}}{6 k^{2}(1-\phi)^{2}}\right\} \frac{T}{2}, \\
& A_{5}=\frac{C_{1} q^{2} T}{12} \text { dan } \theta, d>0 .
\end{aligned}
$$

\section{Solusi Numerik}

Dalam tulisan ini, model diilustrasikan dengan contoh numerik dimana parameterparameter yang digunakan berdasarkan kasus model persediaan economic production quantity pada tulisan De, et.al [2], yaitu : $C_{1}=10, b=500, p=3, r=1$, $k=10, \phi=0,005, d=2, \theta=0,004$ dan $T=40$. Solusi optimal pada model dapat dilihat pada tabel 1 .

Table 1. Solusi Optimal

\begin{tabular}{|c|c|c|}
\hline & $q^{*}$ & $Z^{*}$ \\
\hline Tanpa Deteriorasi & 15,82133 & 5056,867 \\
\hline Dengan Deteriorasi & 15,91341 & 5075,768 \\
\hline
\end{tabular}

Selanjutnya, dilakukan uji sensitivitas terhadap variabel keputusan $q^{*}$ dan $Z^{*}$, ketika parameter-parameter $C_{1}, b, k, p, r, \phi$ dan $T$ berubah sebesar $+50 \%,+20 \%$, $+10 \%,-10 \%,-20 \%$ dan $-50 \%$. 
Table 2 Analisis Sensitivitas

\begin{tabular}{|c|c|c|c|c|c|c|c|}
\hline \multicolumn{4}{|c|}{ Tanpa deteriorasi } & \multicolumn{4}{|c|}{ Dengan deteriorasi } \\
\hline Parameter & $\begin{array}{l}\text { Perubahan } \\
(\%)\end{array}$ & $q^{*}$ & $Z^{*}$ & Parameter & $\begin{array}{l}\text { Perubahan } \\
(\%)\end{array}$ & $q^{*}$ & $Z^{*}$ \\
\hline \multirow[t]{6}{*}{$C_{1}$} & +50 & 12,91806 & 6193,282 & \multirow[t]{6}{*}{$C_{1}$} & +50 & 12,98046 & 6211,638 \\
\hline & +20 & 14,44283 & 5539,482 & & +20 & 14,52017 & 5558,124 \\
\hline & +10 & 15,08505 & 5303,667 & & +10 & 15,16911 & 5322,430 \\
\hline & -10 & 16,67715 & 4797,386 & & -10 & 16,77896 & 4816,446 \\
\hline & -20 & 17,68878 & 4523,042 & & -20 & 17,80265 & 4542,294 \\
\hline & -50 & 22,37474 & 3575,863 & & -50 & 22,55193 & 3595,998 \\
\hline \multirow[t]{6}{*}{$b$} & +50 & 19,37709 & 6193,282 & \multirow[t]{6}{*}{$b$} & +50 & 19,51839 & 6220,762 \\
\hline & +20 & 17,33140 & 5539,482 & & +20 & 17,44308 & 5561,834 \\
\hline & +10 & 16,59355 & 5303,667 & & +10 & 16,69542 & 5324,298 \\
\hline & -10 & 15,00943 & 4797,386 & & -10 & 15,09177 & 4814,550 \\
\hline & -20 & 14,15103 & 4523,042 & & -20 & 14,22366 & 4538,459 \\
\hline & -50 & 11,18737 & 3575,863 & & -50 & 11,23120 & 3585,958 \\
\hline \multirow[t]{6}{*}{$k$} & +50 & 15,19697 & 5264,611 & \multirow[t]{6}{*}{$k$} & +50 & 15,27620 & 5287,224 \\
\hline & +20 & 15,49972 & 5161,784 & & +20 & 15,58512 & 5182,542 \\
\hline & +10 & 15,64346 & 5114,361 & & +10 & 15,73182 & 5134,276 \\
\hline & -10 & 16,04720 & 4985,696 & & -10 & 16,14407 & 5003,358 \\
\hline & -20 & 16,34363 & 4895,277 & & -20 & 16,44689 & 4911,389 \\
\hline & -50 & 18,28808 & 4374,837 & & -50 & 18,43644 & 4382,551 \\
\hline \multirow[t]{6}{*}{$p$} & +50 & 15,82133 & 5056,867 & \multirow[t]{6}{*}{$p$} & +50 & 15,90855 & 5077,294 \\
\hline & +20 & 15,82133 & 5056,867 & & +20 & 15,91147 & 5076,379 \\
\hline & +10 & 15,82133 & 5056,867 & & +10 & 15,91244 & 5076,073 \\
\hline & -10 & 15,82133 & 5056,867 & & -10 & 15,91438 & 5075,463 \\
\hline & -20 & 15,82133 & 5056,867 & & -20 & 15,91536 & 5075,158 \\
\hline & -50 & 15,82133 & 5056,867 & & -50 & 15,91827 & 5074,242 \\
\hline \multirow[t]{6}{*}{$r$} & +50 & 15,82133 & 5057,068 & \multirow[t]{6}{*}{$r$} & +50 & 15,91340 & 5075,972 \\
\hline & +20 & 15,82133 & 5056,948 & & +20 & 15,91341 & 5075,850 \\
\hline & +10 & 15,82133 & 5056,907 & & +10 & 15,91341 & 5075,809 \\
\hline & -10 & 15,82133 & 5056,827 & & -10 & 15,91341 & 5075,728 \\
\hline & -20 & 15,82133 & 5056,787 & & -20 & 15,91341 & 5075,687 \\
\hline & -50 & 15,82133 & 5056,666 & & -50 & 15,91342 & 5075,565 \\
\hline \multirow[t]{6}{*}{$\phi$} & +50 & 15,82634 & 5055,467 & \multirow[t]{6}{*}{$\phi$} & +50 & 15,91852 & 5074,343 \\
\hline & +20 & 15,82333 & 5056,308 & & +20 & 15,91545 & 5075,199 \\
\hline & +10 & 15,82233 & 5056,588 & & +10 & 15,91443 & 5057,484 \\
\hline & -10 & 15,82033 & 5057,146 & & -10 & 15,91239 & 5076,052 \\
\hline & -20 & 15,81933 & 5057,425 & & -20 & 15,91137 & 5076,336 \\
\hline & -50 & 15,81634 & 5058,259 & & -50 & 15,90833 & 5077,186 \\
\hline \multirow[t]{6}{*}{$T$} & +50 & 15,82133 & 7585,301 & \multirow[t]{6}{*}{$T$} & +50 & 15,91341 & 7613,653 \\
\hline & +20 & 15,82133 & 6068,241 & & +20 & 15,91341 & 6090,922 \\
\hline & +10 & 15,82133 & 5562,554 & & +10 & 15,91341 & 5583,345 \\
\hline & -10 & 15,82133 & 4551,180 & & -10 & 15,91341 & 4568,192 \\
\hline & -20 & 15,82133 & 4045,494 & & -20 & 15,91341 & 4060,615 \\
\hline & -50 & 15,82133 & 2528,434 & & -50 & 15,91341 & 2537,884 \\
\hline
\end{tabular}

Dari tabel 2 dapat disimpulkan bahwa hasil uji sensitivitas perubahan parameter sebesar $+50 \%,+20 \%,+10 \%,-10 \%,-20 \%$ dan $-50 \%$ mempunyai pengaruh terhadap $q^{*}$ dan $Z^{*}$. Parameter $C_{1}$ dan $b$ sensitif dan $k$ sedikit sensitif, parameter $p, r$ dan $\phi$ tidak sensitif. Sedangkan parameter $T$, sensitif untuk $Z^{*}$ dan tidak sensitif untuk $q^{*}$. 


\section{Penutup}

Hasil solusi optimum dari kedua model tidak memiliki perbedaan yang signifikan. Tetapi, model persediaan tanpa deteriorasi memiliki solusi optimum sedikit lebih kecil jika dibandingkan dengan model persediaan dengan deteriorasi. Hal ini disebabkan karena adanya penambahan biaya kerusakan (deteriorasi). Kedua model EPQ diilustrasikan dengan contoh yang diselesaikan secara numerik, diperoleh hasil bahwa model dengan deteriorasi harus memproduksi barang sedikit lebih banyak dan mengeluarkan tambahan biaya persediaan. Hasil simulasi memperlihatkan bahwa dari perubahan parameter-parameter sebesar $+50 \%,+20 \%,+10 \%$, $-10 \%,-20 \%$ dan $-50 \%$ menunjukkan bahwa parameter $C_{1}$ dan $b$ sensitif dan $k$ sedikit sensitif, parameter $p, r$ dan $\phi$ tidak sensitif. Sedangkan parameter $T$, sensitif untuk $Z^{*}$ dan tidak sensitif untuk $q^{*}$.

\section{Ucapan Terima kasih}

Penulis mengucapkan terima kasih kepada Ibu Arrival Rince Putri, M.T, M.Si, Bapak Efendi, M.Si, Bapak Dr. Mahdhivan Syafwan, Bapak Bukti Ginting, M.Si dan Bapak Budi Rudianto, M.Si yang telah memberikan masukan dan saran sehingga paper ini dapat diselesaikan dengan baik.

\section{Daftar Pustaka}

[1] Bawono, Baju, T.J. Ai and R.D. Astanti. 2013. Hibah Bersaing. Pengembangan Model dan Solusi Economic Production Quantity Untuk kondisi Sistem Produksi Tidak Sempurna dan Shortage Untuk Peningkatan Produktivitas dan Daya Saing Suatu Industri Manufaktur. Universitas Atma Jaya Yogyakarta. Yogyakarta.

[2] De, S.K., P.K. Kundu and A. Goswami. 2003. "An Economic Production Quantity Inventory Model Involving Fuzzy Demand Rate and Fuzzy Deterioration Rate". J. Appl. Math. \& Computing. 2 : 251-260.

[3] JR, Frank Ayres. 1990. Seri Buku Schaum Teori dan Soal-Soal Persamaan Diferensial dalam Satuan SI Metric. Diterjemahkan oleh: Dra. Lily Ratna. Jakarta: Penerbit Erlangga.

[4] Ghare, P.M., G.P. Schrader. 1963. "A Model for Exponentially Decaying Inventory". J. Ind. Eng. $14:$ 203-211.

[5] Sitepu, Y. L. P., D. Sebayang and U. Sinulingga. 2013. "Pengendalian Persediaan Produksi Crude Palm Oil (CPO) Menggunakan Model Economic Production Quantity (EPQ) Pada PKS. PT. ABC". Saintia Matematika. 1(5): 495-506.

[6] Tersine, R.J. 1994. Principles of Inventory and Management. New Jersey : Prentice Hall. 